\title{
Improvement in Left Ventricular Dysfunction After Surgical Correction of Mitral Regurgitation
}

\author{
Antônio Sérgio Cordeiro da Rocha, Nazareth de Novaes da Rocha, Rita de Cássia Villela Soares, \\ Marialda Coimbra, Rosana Grandelle Ramos, Clara Weksler, Fernando Eugênio Cruz Filho, \\ Celso Garcia da Silveira, Paulo Roberto Dutra da Silva
}

Rio de Janeiro, RJ - Brazil

Objective - To evaluate whether left ventricular endsystolic (ESD) diameters $\leq 51 \mathrm{~mm}$ in patients ( $\mathrm{pt}$ ) with severe chronic mitral regurgitation (MR) are predictors of a poor prognosis after mitral valve surgery (MVS).

Methods - Eleven pt (aged 36 13 years) were studied in the preoperative period (pre), median of 36 days; in the early postoperative period (post 1), median of 9 days; and in the late postoperative period (post2), mean of $38.5 \pm 37.6$ months. Clinical and echocardiographic data were gathered from each $p t$ with MR and systolic diameter $\geq 51 \mathrm{~mm}$ (mean $=57 \pm 4 \mathrm{~mm}$ ) to evaluate the result of $M V S$. Ten patients were in NYHA Class III/IV.

Results - All but 2 pt improved in functional class. Two pt died from heartfailure and infectious endocarditis 14 and 11 months, respectively, after valve replacement. According to ejection fraction (EF) in post 2 , we identified 2 groups: group $1(n=6)$, whose EF decreased in post1, but increased in post $2(p=0.01)$ and group $2(n=5)$, whose $E F$ decreased progressively from post 1 to post $2(p=0.10)$. All pt with symptoms lasting $\leq 48$ months had improvement in EF in post $2(p=0.01)$.

Conclusion - ESD $\geq 51 \mathrm{~mm}$ are not always associated with a poor prognosis after MVS in patients with MR. Symptoms lasting up to 48 months are associated with improvement in left ventricular function.

Keywords: mitral regurgitation, left ventricular dysfunction, surgical correction, mitral valvar correction

From Division of Cardiac Surgery of Instituto Nacional de Cardiologia Laranjeiras National Institute of Cardiology Laranjeiras - Ministério da Saúde Health Ministery, Rio de Janeiro

Mailing address: Antônio Sérgio Cordeiro da Rocha - Rua Roberto Dias Lopes, 220/201 - 22010-110 - Rio de Janeiro, RJ - E-mail: ascrbr@centroin.com.br
Left ventricular function is the main predictive factor of morbidity and mortality after surgical correction of severe chronic mitral regurgitation ${ }^{1}$. Several indexes of left ventricular function assessment have been studied to help the prognosis of this disease after mitral valve replacement ${ }^{1-7}$. Even small enhancements in end-systolic left ventricular diameter in the preoperative period imply an increased risk of left ventricular dysfunction in the postoperative period ${ }^{1,4}$. Because of the poor surgical results found in patients with mitral regurgitation and end-systolic diameter $\geq 51 \mathrm{~mm}$, an alternative treatment has been proposed for these patients ${ }^{4}$. The present study was performed to assess clinical evolvement and left ventricular function through echocardiography, after mitral valve replacement in patients with mitral regurgitation and systolic diameter $\geq 51 \mathrm{~mm}$ and to verify which clinical, echocardiographic, and surgical factors influenced the results.

\section{Methods}

Between January 1988 and May 1997, 253 patients underwent valvar replacement at the Cardiac Surgery Division in of the National Cardiology Laranjeiras Institute, Health Ministry, State of Rio de Janeiro. Fifty-three patients underwent mitral valve replacement for isolated or predominant mitral regurgitation (mitral valve area $\geq 1.7 \mathrm{~cm}^{2}$ ). All 53 patients had adequate color Doppler or bidimensional Doppler echocardiography. Of the 53 patients, 11 who had systolic diameter $\geq 51 \mathrm{~mm}$ (mean $=57 \pm 4 \mathrm{~mm}$, ranging from 51 to $65 \mathrm{~mm}$ ) were selected for the study. Mitral regurgitation was considered severe based on the clinical picture and on Doppler echocardiography evaluation ${ }^{8,9}$. Exclusion criteria included acute mitral regurgitation or mitral regurgitation with symptoms lasting less than 6 months, previous cardiac surgery, moderate or severe aortic valvar disease, congenital cardiopathy, coronary artery disease, or dilated cardiomyopathy. Patients undergoing tricuspid annuloplasty were in- 
cluded in the study. Preoperative clinical data and some relevant surgical data are found in table I. The group was composed by 5 women and 6 men with a mean age of $36 \pm 13$ years. The duration of symptoms was defined as the interval between the beginning of dyspnea Functional Class (FC) II of the New York Heart Association (NYHA) and the date of surgery. One patient was in FC II, 2 were in FC III, and 8 were in FC IV. Nine patients had atrial fibrillation. Four had rheumatic mitral regurgitation, and 7 had degenerative mitral regurgitation ( 5 patients with chordal rupture) based on echocardiographic, surgical, and anatomicopathological findings. All patients older than 40 years underwent cardiac catheterization to exclude coronary artery disease.

All patients received digoxin, diuretics, and angiotensin-converting enzyme inhibitors in the postoperative period. Warfarin was used in the first 3 months after surgery in those patients who received biological prostheses and indefinitely in those patients who received mechanical prostheses, had atrial fibrillation, or received medical prescription.

All patients underwent bidimensional transthoracic color or conventional Doppler echocardiography, with commercially available equipment (Apogee CX200 and Interspect). The semiquantitative assessment of mitral regurgitation was determined on a scale of $1+$ to $4+$ degrees $^{8,9}$. Echocardiographic measures performed in the unidimensional mode were guided by the bidimensional mode. Left ventricular end-diastolic and end-systolic diameter and ventricular wall thickness were obtained at the papillary muscles level in the parasternal plane. Left atrium diameter was assessed during systole. Cardiac diameters and left ventricular mass were indexed through body surface. Left ventricular ejection fraction was assessed according to the recommendations of the American Association of Echocardiography ${ }^{10,11}$. In patients with atrial fibrillation, a mean of 5 beats was obtained. Mitral valvar area was assessed by the pressure-half-time method. Echocardiography included the last preoperative examination (pre), median of 29 days (ranging from 12 to 120 days); early postoperative examination (post1), median of 9 days (ranging from 6 to 140 days); and the most recent available examination in the postoperative follow-up (post2), mean $38.5 \pm 37.6$ months. In post 2 , no signs existed of mitral regurgitation. Two patients with rheumatic mitral regurgitation had mild aortic regurgitation in the preoperative period that remained unchanged in post 1 and post 2 .

Surgical procedures were performed with cardiopulmonary derivation and moderate systemic hypothermia (between 28 and $32^{\circ} \mathrm{C}$ ). Myocardial protection was obtained with a hypothermic blood solution (between 10 and $15^{\circ}$ ) and enriched with potassium aspartate and potassium glutamate at a $24 \mathrm{mEq} / \mathrm{L}$ concentration. A cardioplegic solution was infused intermittently for 3 minutes every 15 minutes; the last infusion was previously heated at $37^{\circ} \mathrm{C}$ with a potassium concentration of $10 \mathrm{mEq} / \mathrm{L}$. One patient underwent mitral valve repair with the Carpentier technique ${ }^{12,13}$, which consisted of the quadrangular resection of valvar tissue followed by suture and placement of a Carpentier ring. The other
10 patients underwent mitral valve replacement, with chordal preservation in 9 patients (preservation of chodal tendineae to the posterior leaflet in all patients). Nine biological prostheses of bovine pericardium $\left(\right.$ Labcor $\left.^{\circledR}\right)$ and one bileaflet mechanical prostheses $\left(\right.$ Carbomedics $\left.^{\circledR}\right)$ were implanted. Prostheses size was 33 in 5 patients and 35 in the other 5 . Three patients underwent tricuspid annuloplasty with the De Vega technique. Two patients needed left atrium reduction surgery (atrial tissue resection around the atrial ostia) due to a left aneurysmatic atrium. Precocious death did not occur (precocious death was defined as death that occurred in the first 30 days after surgery or during hospitalization). Reoperation was necessary in one patient because of bleeding in the postoperative period.

Clinical data were prospectively collected by one of the authors, and the follow-up data were collected during the ambulatory visit. Patients were followed-up until death or until the last scheduled ambulatory visit. Mean follow-up was $39 \pm 18.7$ months (ranging from 9 to 69 months).

Data are expressed as mean \pm SD. Statistical computer software EpiInfo 6.0 and SPSS 8.0 for Windows were used for statistical analysis. Paired or unpaired Student $t$ test for continuous data and the analysis of variance (ANOVA) were used to compare continuous variables. Scheffe's method was used to discriminate significant differences found at ANOVA. Fisher's exact test was used for comparison between categoric variables. Pearson's correlation was used to correlate the variables. Probability of survival and survival free from severe symptoms (NYHA FC $\geq 3$ ) was estimated with the Kaplan-Meier method. A p $<0.05$ was considered significant.

\section{Results}

Functional class improved in the postoperative period in all but 2 patients. One remained in Functional Class IV (severe congestive heart failure) and died 14 months after surgery. Another patient was in Functional Class III 44.7 months after surgery (table I). In the last ambulatory visit, 8 patients were in Functional Class I and 1 was in Functional Class II, including one whose Functional Class improved in the postoperative period, but who died due to infective endocarditis 11 months after surgery. Survival rates at 5-year follow-up was $81.8 \pm 11.6 \%$ (95\% confidence interval raging from 16 to $99 \%$ ), and the survival rates for patients free from significant symptoms at 5-year follow-up was $67.5 \pm 23.7 \%$ (95\% confidence interval ranging from 13 to $96 \%$ ).

Evolvement of left ventricular diameters and left ventricular function in the postoperative period: As expressed in table II, a significant decrease in left ventricular end-diastolic diameter (EDD) occurred between pre, and post 1 and post 2 ( $p=0.001)$; however, no significant difference occurred between post 1 and post $2(\mathrm{p}=\mathrm{NS})$. Despite the reduction in end-systolic diameter in post 1 and post 2 compared with that in the pre, this difference did not reach statistical significance $(p=0.33)$, nor did the ejection fraction $(p=0.13)$ or left ventricular shortening fraction $(p=0.16)$. According to the 


\begin{tabular}{|c|c|c|c|c|c|c|c|c|c|c|c|c|}
\hline Patients & G & A & Causes & $\begin{array}{l}\text { Symptoms } \\
\text { (months) }\end{array}$ & $\begin{array}{l}\text { FC } \\
\text { Pre }\end{array}$ & FA & $\begin{array}{l}\mathrm{SC} \\
\left(\mathrm{m}^{2}\right)\end{array}$ & $\begin{array}{c}\text { Type of } \\
\text { Surgery }(*)\end{array}$ & $\begin{array}{c}\text { Chordal } \\
\text { preservation }\end{array}$ & $\begin{array}{c}\text { Tricuspid } \\
\text { annuloplasty }\end{array}$ & $\begin{array}{l}\text { TCA } \\
(\mathrm{min})\end{array}$ & $\begin{array}{c}\mathrm{CF} \\
\text { post2 }\end{array}$ \\
\hline 1 & $\mathrm{~F}$ & 50 & $\operatorname{deg}$ & 60 & III & yes & 1.38 & MVR & - & yes & 84 & II \\
\hline 2 & $\mathrm{~F}$ & 26 & deg & 120 & IV & yes & 1.59 & $\operatorname{MVRe}(33)$ & yes & yes & 55 & IV \\
\hline 3 & $\mathrm{~F}$ & 54 & deg & 120 & IV & yes & 1.43 & MVRe(33) & yes & no & 80 & III \\
\hline 4 & M & 53 & deg & 172 & IV & no & 1.75 & MVRe(35) & no & no & 80 & II \\
\hline 5 & F & 24 & rheu & 72 & IV & yes & 1.75 & MVRe(35) & yes & no & 84 & I \\
\hline 6 & M & 31 & deg & 48 & IV & yes & 1.62 & $\operatorname{MVRe}(35)$ & yes & no & 13 & I \\
\hline 7 & $\mathrm{~F}$ & 29 & rheu & 12 & IV & yes & 1.39 & $\operatorname{MVRe(33)}$ & yes & yes & 49 & I \\
\hline 8 & M & 25 & deg & 36 & IV & yes & 1.85 & $\operatorname{MVRe}(35)$ & yes & no & 50 & I \\
\hline 9 & M & 57 & deg & 24 & III & no & 1.60 & MVRe(33) & yes & no & 65 & I \\
\hline 10 & M & 31 & rheu & 24 & II & yes & 1.93 & MVRe(35) & yes & no & 54 & I \\
\hline 11 & M & 22 & rheu & 60 & IV & yes & 1.55 & MVRe(33) & yes & no & 70 & I \\
\hline Mean & & 36 & & 68 & & & 1.62 & & & & 62.1 & \\
\hline SD & & 13 & & 49.7 & & & 0.1 & & & & 21.2 & \\
\hline
\end{tabular}

ejection fraction in post 2 , we can analyze 2 groups of patients (table III). In 6 patients, group 1, a significant and continuous reduction in the diastolic $(\mathrm{p}=0.0004)$ and systolic diameters occurred $(\mathrm{p}=0.001)$ from pre to post 2 . In this group, ejection fraction did not decrease significantly from pre to post 1 , but increased significantly from post 1 to post 2 $(\mathrm{p}=0.01)$. In the other 5 patients, group 2 , a nonsignificant decrease in diastolic $(\mathrm{p}=0.25)$ and systolic diameters $(\mathrm{p}=0.55)$ occurred in post 1 , followed by a nonsignificant increase in post 2 . In this group, ejection fraction decreased gradually and not significantly from pre to post 1 and from post 1 to post $2(\mathrm{p}=0.10)$.

No correlation was found between echocardiographic data in pre and post 1 or post 2 . No difference existed between sex, age, Functional Class, body surface, cause of mitral regurgitation, atrial fibrillation, tricuspid valve disease, left atrium dimension, diastolic diameter, systolic diameter, ejection fraction, shortening fraction, septal thickness, and left ventricular posterior wall thickness, left ventricular mass in the pre, aortic clamping time, chordal preservation, tricuspid annuloplasty, left atrium shortening surgery, and size of the prostheses implanted in the patients of groups 1 and 2 . However, persistence of symptoms in patients from group $1,30 \pm 12$ months, was significantly lower than that in those patients from group $2,79 \pm 38.5$ months $(p=0.01)$. A good inverse correlation was found between the persistence of symptoms and the ejection fraction in post $2(\mathrm{r}=-0.82$, $\mathrm{p}<0.01$ ), and a direct correlation was found between the duration of symptoms and the systolic diameter $(\mathrm{r}=0.94$, $\mathrm{p}<0.001$ ). All 5 patients with symptoms lasting $\leq 48$ months had improved ejection fraction in post 2 , whereas only 1 of the 6 patients with symptoms lasting $>48$ months had ejection fraction improvement in post $2(\mathrm{p}=0.01)$.

\section{Discussion}

Results of this study indicate that some patients with severe symptomatic chronic mitral regurgitation and severe preoperative left ventricular dysfunction may improve in Functional Class and left ventricular function, later, after mitral valve replacement. These results are not in accordance with those of previous studies, which demonstrated a poor prognosis in patients with severe mitral regurgitation and severe left ventricular dysfunction after mitral valve replacement. Starling ${ }^{14}$, studying 15 patients with chronic mitral regurgitation 1 year after mitral valve replacement, demonstrated the persistence of left ventricular dysfunction in those patients whose end-diastolic and end-systolic volumes were increased and whose ejection fraction was decreased in the preoperative period. Wisenbaugh et al ${ }^{4}$, reporting the postoperative results of 61 patients with mitral regurgitation, demonstrated that systolic diameter

\begin{tabular}{|c|c|c|c|c|}
\hline & $\begin{array}{l}\text { EDD } \\
(\mathrm{mm})\end{array}$ & $\begin{array}{l}\text { EDS } \\
(\mathrm{mm})\end{array}$ & $\begin{array}{c}\mathrm{EF} \\
(\%)\end{array}$ & $\begin{array}{l}\text { SHF } \\
(\%)\end{array}$ \\
\hline Pre & $79 \pm 6$ & $57 \pm 4$ & $47 \pm 7$ & $27 \pm 5$ \\
\hline Post1 & $63 \pm 9 *$ & $51 \pm 9$ & $35 \pm 15$ & $19 \pm 9$ \\
\hline Post2 & $64,5 \pm 14^{*}$ & $50 \pm 17$ & $41 \pm 18$ & $23 \pm 14$ \\
\hline $\mathrm{p}$ & 0.001 & 0.33 & 0.13 & 0.16 \\
\hline
\end{tabular}




\begin{tabular}{|c|c|c|c|c|c|c|c|c|}
\hline \multicolumn{9}{|c|}{ Table III - Preoperative data (pre), early postoperative (post1), and late postoperative (post2) in patients from group 1 and group 2} \\
\hline & \multicolumn{3}{|c|}{$\begin{array}{l}\text { Group } 1 \\
(\mathrm{n}=6)\end{array}$} & \multirow[b]{2}{*}{$\mathrm{P}$} & \multicolumn{3}{|c|}{$\begin{array}{l}\text { Group } 2 \\
(\mathrm{n}=5)\end{array}$} & \multirow[b]{2}{*}{$\mathrm{P}$} \\
\hline & Pre & Post 1 & Post2 & & Pre & Post 1 & Post2 & \\
\hline $\operatorname{EDD}(\mathrm{mm})$ & $79 \pm 5$ & $63 \pm 8^{*}$ & $59 \pm 7 * *$ & 0.004 & $77 \pm 8$ & $63 \pm 11$ & $70 \pm 17$ & 0.25 \\
\hline $\mathrm{EDS}(\mathrm{mm})$ & $58 \pm 5$ & $50 \pm 9 \ddagger$ & $40 \pm 4^{* *}$ & 0.001 & $56 \pm 2$ & $52 \pm 11$ & $61 \pm 20$ & 0.55 \\
\hline $\mathrm{EF}(\%)$ & $46 \pm 6$ & $37 \pm 14,5 \neq$ & $55 \pm 3$ & 0.01 & $47 \pm 10$ & $32 \pm 16$ & $26 \pm 16$ & 0.10 \\
\hline SHF (\%) & $26 \pm 4$ & $21 \pm 9 \ddagger$ & $32 \pm 2$ & 0.02 & $27 \pm 6$ & $18 \pm 9$ & $14 \pm 9$ & 0.07 \\
\hline
\end{tabular}

was the most useful predictor of death, heart failure, and left ventricular dysfunction. Of 8 patients with systolic diameter $\geq 51 \mathrm{~mm}, 6$ died and 1 remained with severe heart failure. One patient remained with severe left ventricular dysfunction but had an improvement in Functional Class after a mean follow-up of 24 months. Based on these results, they consider surgery in these patients, even with chordal preservation, "heroic", and they suggest that an alternative surgery should, therefore, be considered for these patients. In our patients, although they had the same level of preoperative left ventricle dysfunction, we did not observe the same results in the postoperative period. The rate of survivors at 5 years was $81.8 \%$. We observed that only 2 patients remained with advanced heart failure (1 died 14 months after surgery), whereas the 9 remaining patients improved their Functional Class. The other death observed resulted from infective endocarditis in 1 patient who had improved Functional Class and left ventricular function. Although they had improved Functional Class, 2 other patients still had severe left ventricular dysfunction in post2. Therefore, the rate of survivors free from important symptoms, in 5 years, was $67.5 \%$. In contrast with the South African study ${ }^{4}$, rheumatic disease was not the only cause found in our patients that could explain the difference in our results. However, our patients with mitral regurgitation had a decrease in systolic diameter and improvement in Functional Class.

Ejection fraction reduction is a common finding after mitral valve replacement, even with chordal preservation and mitral valve repair ${ }^{4,15-18}$. Ejection fraction and shortening fraction decrease in the postoperative period is also observed in those patients with preserved left ventricular function in the preoperative period ${ }^{4,19,20}$. It has been believed that in patients with "noncompensated" mitral regurgitation, cardiac chambers enlargement persists after mitral valve replacement because of the increase in final systolic stress, which further decreases systolic function. However, in this study, we have demonstrated that in some patients with noncompensated mitral regurgitation a decrease in left ventricular dimensions occurred, and therefore a consequent improvement in left ventricular function was observed.

Bonow et al ${ }^{21}$, studying patients with severe aortic regurgitation, observed that prolonged left ventricular dys- function ( $\geq 1$ year) resulted in a greater chance of left ventricular dysfunction after aortic valve replacement. Recently, Krishman et al ${ }^{22}$, studying children operated on for severe mitral regurgitation, reported an early worsening, followed by a late improvement in left ventricular function. The improvement was explained by a relatively shorter overall duration of mitral insufficiency or a greater potential for recovery in younger myocardium. These results are very similar to ours, especially in group 1, whose left ventricular dysfunction decreased precociously (post1) but improved later (post2) after mitral valve replacement, suggesting a level of contractile reserve in these patients. They had a lower duration of symptoms compared with that in those whose left ventricular function decreased in the postoperative period ( $30 \pm 12$ and $79 \pm 38.5$ months, respectively, $\mathrm{p}=0.01$ ). We have also observed that patients whose symptoms persisted for $\leq 48$ months had an improvement in ejection fraction in post 2 compared with that in those with symptoms lasting $>48$ months $(\mathrm{p}=0.01)$. In addition, we verified a good relationship between symptoms duration and ejection fraction in post $2(\mathrm{r}=-0.82, \mathrm{p}<0.01)$. More recently, Tribouilloy et al ${ }^{23}$, studying the influence of Functional Class on the surgical results in patients with mitral regurgitation, demonstrated that patients in Functional Class III/IV had higher operative mortality and lower late survival than those patients in Functional Class I/II, regardless of left ventricular function, age, or other clinical features. Although no systematic studies that correlate the presence and the severity of symptoms with the level grade of left ventricular dysfunction are available in severe chronic mitral regurgitation, we should consider the findings of Tribouilloy et al ${ }^{23}$ where patients with mitral regurgitation in Functional Class IV had lower ejection fraction than those patients in Functional Class I/II. In our study, no differences existed in left ventricular function between the patients in different Functional Classes, because of the selection criteria used and the small number of enrolled patients. Fuster et al ${ }^{24}$ demonstrated that patients with severe chronic mitral regurgitation and advanced symptoms, and in Functional Class III/IV, had more myocardial interstitial tissue than those patients in Functional Class I/II without heart disease. Unfortunately, neither Tribouilloy et al ${ }^{23}$ nor Fuster et al ${ }^{24}$ mentioned the duration of symptoms of the patients involved in their 
studies. Therefore, it is possible to confirm that the amount of myocardial interstitial tissue is less intense in patients with a shorter duration of symptoms. This may be the explanation for the improvement observed in our patients with a duration of symptoms $\leq 48$ months.

According to our findings, conventional mitral valve surgery, with chordal preservation, or mitral valve repair must be recommended to patients with mitral regurgitation and systolic diameter $\geq 51 \mathrm{~mm}$, even though some of them may remain with severe left ventricular dysfunction, but with a great chance of improving in Functional Class. Additionally, we may evaluate the late postoperative result and decide on an alternative treatment, such as cardiac transplantation. Duration of symptoms $\leq 48$ months identifies the patients with greater chances of left ventricular function improvement after mitral valve replacement in patients with mitral regurgitation and systolic diameter $\geq 51 \mathrm{~mm}$.

In this study, we did not assess systolic stress indexes ${ }^{25}$, left ventricle cavity elastance ${ }^{14}$, ejection fraction variance, or systolic diameter during exercise ${ }^{7}$; therefore, we do not know whether they could influence the postoperative results. However, we do not know any studies that have demonstrated that these indexes have greater predictive value than the diastolic diameter. We do not know either how long left ventricular dysfunction persisted in the patients included in the study, because a few patients had echocardiographic examinations at the onset of their diseases. Additionally, our results do not apply to asymptomatic or to minimally symptomatic patients with chronic mitral regurgi- tation, because most of our patients had severe symptoms (Functional Class III/IV) before surgery. We could not assess the influence on the results of the surgical technique performed, once the number of patients is small to enable such a comparison. We do not know either whether the use of angiotensin-converting enzyme inhibitors played any role in the improvement of left ventricular function or in Functional Class determination. However, all patients from both groups used these medications during the postoperative follow-up. Further studies involving a greater number of patients are necessary to confirm our results. We want to point out that the population studied was composed of a special group of patients with severe mitral regurgitation in an advanced stage of the disease who ought medical treatment. In our service, we recommend mitral valve surgery for patients with mitral regurgitation that become symptomatic and for those with severe mitral regurgitation asymptomatic or minimally symptomatic, when a real chance exists of mitral valve repair regardless of left ventricular dimensions.

In summary, systolic diameter $\geq 51 \mathrm{~mm}$ is not always associated with a poor prognosis in the postoperative period. In most patients with severe chronic mitral regurgitation and systolic diameter $\geq 51 \mathrm{~mm}$, Functional Class improves regardless of the response of left ventricular function after surgery. Duration of symptoms $\leq 48$ months is associated with a greater chance of improvement in left ventricular function.

\section{References}

1. Stewart WJ. Choosing the "Golden Moment" for operation in the era of valve repair for mitral regurgitation. ACC Highlights 1995; 10: 2-7.

2. Zile MR, Gaasch WH, Carrol JD, Levine HJ. Chronic mitral regurgitation: predictive value of preoperative echocardiographic indexes of left ventricular function and wall stress. J Am Coll Cardiol 1984; 3: 235-42.

3. Borow KM, Green LH, Mann T, et al. End-systolic volume as a predictor of postoperative left ventricular performance in volume overload from valvular regurgitation. Am J Med 1980; 68: 655-63.

4. Wisenbaugh T, Skundicky D, Sareli P. Prediction of outcome after valve replacement for rheumatic mitral regurgitation in the era of chordal preservation. Circulation 1994; 89: 191-7.

5. Nakano S, Sakai K, Tamiguchi K, etal. Relation of impaired left ventricular function in mitral regurgitation to left ventricular contractile state after mitral valve replacement. Am J Cardiol 1994; 73: 70-4.

6. Pai RG, Bausal RC, Shah PM. Doppler-derived rate of left ventricular pressure rise: its correlation with the postoperative left ventricular function in mitral regurgitation. Circulation 1990: 82: 514-20.

7. Leung DY, Grifin BP, Stewart WJ, Cosgrove DM, Thomas JD, Marwick TH. Left ventricular function after valve repair for chronic mitral regurgitation: predictive value of preoperative assessment of contractile reserve by exercise echocardiography. J Am Coll Cardiol 1996; 28: 1198-205.

8. Abbasi AS, Allen MW, Decristofaro D, Ungar I. Detection and estimation of the degree of mitral regurgitation by range-gated pulsed Doppler echocardiography. Circulation 1980; 6i: 143-7.

9. Helmcke F, Nanda NC, Hsiung MC, et al. Color Doppler assessment of mitral regurgitation with orthogonal plans. Circulation 1987; 75: 175-83.

10. Schiller NB. Two-dimensional echocardiographic determination of left ventricular volume, systolic function and mass: summary and discussion of the 1989 re- commendations of the American Society of Echocardiography. Circulation 1991; 84(suppl): 1280-7.

11. Teichholz LE, Kreulen T, Herman MV, Gorlin R. Problems in echocardiographic volume determinations: echocardiographic-angiographic correlations in the presence or absence of asynergy. Am J Cardiol 1976; 37: 7-11.

12. Carpentier A, Deloche A, Dauptain J, et al. A new reconstructive operation for correction of mitral and tricuspid insufficiency. J Thorac Cardiovasc Surg 1971; 61: 1-13.

13. Carpentier A. Cardiac valve surgery: the "French correction". J Thorac Cardiovasc Surg 1983; 86: 323-37

14. Starling MR. Effects of valve surgery on left ventricular contractile function in patients with long-term mitral regurgitation. Circulation 1995; 92: 81-818.

15. Schuler G, Peterson KL, Johnson A, et al. Temporal response of left ventricular performance to mitral valve surgery. Circulation 1979; 59: 1218-31.

16. Crawford MH, Souchek J, Oprian CA, et al, and participants in the Department of Veterans Affairs Cooperative Study on Valvular Heart Disease. Determinants of survival and left ventricular performance after mitral valve replacement. Circulation 1990; 81: 1173-81.

17. Enriquez-Sarano M, Tajik AS, SchaffHV, et al. Echocardiographic prediction of left ventricular function after correction of mitral regurgitation: results and clinical implications. J Am Coll Cardiol 1994; 24: 1536-43.

18. Bonow RO, Nikas D, Elefteriades JA. Valve replacement for regurgitant lesions of the aortic and mitral valve in advanced left ventricular dysfunction. Cardiol Clin 1995; 13: 73-83.

19. Enriquez-Sarano M, SchaffHV, Orszulak TA, Tajik AJ, Bailey KR, Frye RL. Valve repair improves the outcome of surgery for mitral regurgitation. A multivariate analysis. Circulation 1995; 91: 1022-8.

20. Starling MR, Kirsh MM, Montgomery DG, Grosss MD. Impaired left ventricular 
contractile function in patients with long-term mitral regurgitation and normal ejection fraction. J Am Coll Cardiol 1993; 22: 239-50.

21. Bonow RO, Rosing DR, Maron BJ, et al. Reversal of left ventricular dysfunction after aortic valve replacement for chronic aortic regurgitation. influence of duration of preoperative left ventricular dysfunction. Circulation 1984; 70: 570-9.

22. Krishman US, Gersony WM, Berman-Rosenzweig E, Apfel HD. Late left ventricular function after surgery for children with chronic symptomatic mitral regurgitation. Circulation 1997; 96: 4280-5.

23. Tribouilloy CM, Enriquez-Sarano M, SchaffHV, et al. Impact of preoperative sym- ptoms on survival after surgical correction of organic mitral regurgitation: rationale for optimizing surgical indications. Circulation 1999: 99: 400-5.

24. Fuster V, Danielson MA, Robb RA, Broadkent JC, Brown AL, Elveback LR. Quantitation of left ventricular myocardial fibre hypertrophy and increased volume and intersticial tissue in humans hearts with chronically increased volume and pressure overload. Circulation 1977: 55: 504-8.

25. Carabello BA, Nolan SP, McGuire LB. Assessment of preoperative left ventricular function in patients with mitral regurgitation: value of the end-systolic wall stress - end-systolic volume ratio. Circulation 1981; 64: 1212-7. 